\title{
Isoform-specific effects of ApoE on neurite outgrowth in Olfactory Epithelium culture
}

\author{
Aseem Hussain, Minh Luong, Apryl Pooley and Britto P Nathan ${ }^{*}$
}

\begin{abstract}
Background: The apolipoprotein E4 (apoE4) genotype is a major risk factor for developing late-onset Alzheimer's disease (AD). Inheritance of apoE4 is also associated with impairments in olfactory function in early stages of AD. In this project we examined the effects of the three common isoforms of human apoE (apoE2, apoE3, and apoE4) on neuronal differentiation and neurite outgrowth in explant cultures of mouse olfactory epithelium (OE).

Results: The OE cultures derived from apoE-deficient/knockout (KO) mice have significantly fewer neurons with shorter neurite outgrowth than cultures from wild-type (WT) mice. Treatment of the apoE KO culture with either purified human apoE2 or with human apoE3 significantly increased neurite outgrowth. In contrast, treatment with apoE4 did not have an effect on neurite outgrowth. The differential effects of human apoE isoforms on neurite outgrowth were abolished by blocking the low-density lipoprotein receptor-related protein (LRP) with lactoferrin and receptor-associated protein (RAP).
\end{abstract}

Conclusion: ApoE2 and apoE3 stimulate neurite outgrowth in OE cultures by interacting with the lipoprotein receptor, LRP. ApoE4, the isoform associated with $A D$, failed to promote neurite outgrowth, suggesting a potential mechanism whereby apoE4 may lead to olfactory dysfunction in AD patients.

Keywords: ApoE, Neurite outgrowth, Neuronal differentiation, Olfaction, Olfactory neurons, Low-density lipoprotein receptor-related protein, Receptor-associated protein, Alzheimer's disease

\section{Background}

Apolipoprotein E (apoE) is a protein component of several lipoproteins [1]. ApoE functions in the redistribution of lipids by binding to the low-density lipoprotein (LDL) receptor and the LDL receptor-related protein (LRP) family members [2]. Receptor-lipoprotein binding initiates internalization and degradation of lipoproteins, making lipids available for use in the regulation of intracellular lipid metabolism. ApoE ranges in length from 279 to 310 residues, with a high degree of sequence similarities among species [3]. There are three major isoforms of apoE in humans differing by amino acids at positions 112 and 158 [4]. The most common isoform, apoE3, contains cysteine and arginine at positions 112 and 158, respectively [3]. Both positions have cysteine in apoE2 and arginine in apoE4. Mice have one form of apoE, which is similar to human apoE3 in its structural

\footnotetext{
* Correspondence: bpnathan@eiu.edu

Department of Biological Sciences, Eastern Illinois University, 600 Lincoln Avenue, Charleston, IL 61920, USA
}

and functional properties, including receptor binding and lipoprotein preferences [3].

Numerous genetic studies have revealed that inheritance of apoE4 allele increases the risk and rate of progression of late-onset Alzheimer disease [5-9]. About $65-80 \%$ of $\mathrm{AD}$ patients have at least one apoE4 allele $[9,10]$. In addition, apoE4 inheritance decreases the age of onset of AD [8,9]. Neurofibrillary tangles and amyloid plaques, the two hallmarks of $\mathrm{AD}$, are increased in brain samples from apoE4 carriers as compared to non-apoE4 carriers $[11,12]$. Both plaques and tangles appear earlier in apoE4 patients as compared to non-apoE4 patients. In addition, $\mathrm{AD}$ patients with apoE4 genotype showed decreased dendritic growth, reduced synaptic numbers, and widespread degeneration of neurons in areas of the brain related to learning and memory, as compared to non-apoE4 patients [13]. Numerous hypotheses have been proposed to explain apoE4 effects on $\mathrm{AD}$; however, the mechanism whereby apoE4 leads to $A D$ is still unclear. 
Inheritance of the apoE4 genotype is also associated with olfactory dysfunction including deficits in odor fluency, odor identification, odor recognition and olfactory threshold sensitivity [14-18]. These olfactory impairments are observed early in the course of $\mathrm{AD}$, even before the onset of clinical dementia [14]. Non-demented apoE4-individuals showed significant decline in olfactory processing as compared to individuals without apoE4 allele $[19,20]$. The AD patients with apoE4 allele showed greater deficits in olfactory tests than siblings without apoE4 allele [21]. Data from longitudinal studies also have shown that apoE4 inheritance is associated with poor scores in olfactory tests [15]. In essence, these findings show that apoE plays a key role in olfactory function.

The mechanism underlying apoE effects on olfactory function is not clear. In previous studies, we showed that apoE is expressed at high levels by a variety of cell types in the olfactory epithelium and its underlying lamina propria [22]. ApoE was localized in the basal cell layer, suggesting that it could promote neurogenesis by facilitating differentiation of basal cells to mature neurons. In addition olfactory nerve regeneration following olfactory nerve lesioning was significantly slower in apoE KO mice as compared to WT mice, suggesting that apoE may play a critical role in olfactory nerve regeneration in mice [23].

In this project we explored this possibility by examining the effects of apoE isoforms on neuronal differentiation and neurite outgrowth in olfactory epithelium (OE) explant cultures. We found that (1) OE cultures derived from apoE KO mice have significantly fewer neurons with shorter neurite outgrowth than cultures from WT mice; (2) treatment of apoE $\mathrm{KO}$ cultures with either purified apoE2 or apoE3 significantly increased neurite outgrowth, whereas treatment with apoE4 had no effect; and (3) the differential effects of human apoE isoforms on neurite outgrowth were abolished by blocking the low-density lipoprotein receptor-related protein (LRP) with lactoferrin and receptor associated protein (RAP).

\section{Methods}

\section{Olfactory explant epithelial culture}

Homozygous apoE KO mice (C57BL/6-Apoe (tmiUnc>) $^{<0}$ bred 10 generations onto $\mathrm{C} 57 \mathrm{BL} / 6$ background and control mice (C57BL/6 J) were obtained from Jackson Laboratory (Bar Harbor, MA). Cell culture medium, including Neurobasal A, Hanks' Balanced Salt Solution, B27 Supplement and FGF2 were obtained from Invitrogen Corporation (Grand Island, NY). Glutamine and fibronectin were purchased from Sigma Chemicals (St. Louis, MO). Costar Brand Tissue Culture 24-well plates were purchased from Fisher Scientific (Chicago, IL).

Prior to each experiment, glass slips were coated with $50 \mu \mathrm{g} / \mathrm{ml}$ fibronectin solution (Invitrogen Grand Island, $\mathrm{NY}$ ) for two hours at $37^{\circ} \mathrm{C}$. For each experiment, seven to eight post-natal pups (2 days old) were decapitated using a sterile surgical scissors and their nasal cavity was cut open sagitally, exposing the OE. The OE was carefully dissected and placed in ice-cold $10 \mathrm{ml}$ of Hanks' Balanced Salt Solution (Invitrogen Grand Island, NY), containing gentamycin $(100 \mu \mathrm{g} / \mathrm{ml})$ and glucose $(6 \mathrm{mg} / \mathrm{ml})$. The $\mathrm{OE}$ was sliced using sterile razor blade into approximately $200 \mu \mathrm{m}$ thick explants. The explants were transferred into Neurobasal-A (NBA) media (Invitrogen Grand Island, $\mathrm{NY})$ containing B27 supplement $(20 \mu \mathrm{l} / \mathrm{ml})$ and glutamine (0.5 mM). The explants were transferred to a 24-well plate containing the fibronectin coated slips, and the explants were incubated for 30 minutes without any media in a humidified incubator at $37^{\circ} \mathrm{C}$ and $5 \% \mathrm{CO}_{2}$. Following incubation, $500 \mu \mathrm{l}$ of growth media (Neurobasal-A medium with $5 \mathrm{ng} / \mathrm{ml} \mathrm{FGF}_{2}$ and B27) was added to each well and the plate was further incubated. New growth media was changed every two days. Cultures were fixed at 8 days in vitro (DIV).

\section{Measurement of neuronal numbers, halo size, and neurite outgrowth}

The OE cultures from WT and apoE $\mathrm{KO}$ mice were grown for 8 days in growth media, fixed with $4 \%$ paraformaldehyde, and cultures were immunostained for tubulin III (neuronal marker) as described below. The number of neurons, radii of the inner and outer halos, and combined length of the short and the long neurite outgrowth was measured using a stage micrometer mounted on an Olympus BX50 fluorescent microscope. A minimum of 60 neurons was measured for each treatment condition. To avoid bias in measurements, all neurons in the visual fields located at 5 quadrants (center, northeast, northwest, southeast and southwest) of the culture on cover slips was measured. In addition, the researcher was unaware of the genotype (WT versus apoE $\mathrm{KO}$ ) and/or the treatment condition.

In experiments with apoE, recombinant human apoE were purchased from Panvera (Madison, WI), and dialyzed overnight in $0.1 \mathrm{M}$ ammonium bicarbonate. The OE cultures at 2 DIV were incubated with medium alone or with apoE isoforms $(5 \mu \mathrm{g} / \mathrm{ml})$. The media was replaced every two days with re-addition of apoE. At 8 DIV, the cultures are fixed, immunostained for tubulin III, and neurite outgrowth measured as described above.

For studies with LRP inhibitors, lactoferrin was obtained from Sigma Chemical (St. Louis, MO), and purified receptor associated protein (RAP) was generously provided by Dr. Dudley Strickland (American Red Cross, Rockville, MD). The OE cultures at 2 DIV were pre-incubated for $1 \mathrm{~h}$ with medium alone or with either RAP $(5 \mu \mathrm{g} / \mathrm{ml})$ or lactoferrin $(10 \mu \mathrm{g} / \mathrm{ml})$. Following incubation, apoE isoforms $(5 \mu \mathrm{g} / \mathrm{ml})$ were added to the medium. The media was replaced every two days with re-addition of 
the test reagents. At $8 \mathrm{DIV}$, the cultures are fixed, immunostained for tubulin III, and neurite outgrowth measured as described above.

\section{Immunocytochemistry}

Immunostaining of neuronal marker, tubulin III, was performed as previously described [24,25]. Briefly, cover slips of cultures at 8 DIV were rinsed with warm phosphate buffered saline (PBS) and fixed with $4 \%$ paraformaldehyde in PBS for $15 \mathrm{~min}$ at room temperature. Cells were permeabilized with $0.5 \%$ Triton in PBS for 10 minutes. Cells were rinsed with PBS and blocked with $5 \%$ donkey serum and $0.05 \%$ Triton in PBS for 60 minutes. Cells were incubated with mouse anti-tubulin III (Sigma Chemicals, St. Louis, MO) at 1:200 dilution in blocking solution for $2 \mathrm{~h}$ at room temperature. Following incubation, cells were rinsed three times with PBS and incubated with TRITC-conjugated donkey anti-mouse (Jackson ImmunoResearch West Grove, PA) in blocking solution at 1:200 for 1h. Cells were rinsed with PBS and were mounted with mounting medium (Vector Laboratories, Burlingame, CA). Immunoreactive cells were counted and photographed on an Olympus BX50 microscope with appropriate excitation filters.

Immunocytochemistry of olfactory sensory neurons using markers for mature (OMP) and immature (GAP43) was performed as described above for tubulin III. At 8 DIV cells were fixed, permeabilized, and blocked with $1 \%$
BSA for 10 minutes. Cells were incubated overnight at $4^{\circ} \mathrm{C}$ with goat anti-OMP (Wako labs, Wako TX) at 1:500 dilution in $4 \%$ donkey serum or with rabbit anti-GAP43 (Millipore, Billerica, MA) at 1:200 dilution in 4\% rabbit serum. Following incubation, cells were rinsed with PBS and incubated for $1 \mathrm{~h}$ at room temperature with Cy3-conjugated donkey anti-goat at 1:500 dilution in 4\% donkey serum or with FITC-conjugated donkey anti-rabbit at 1:1000 dilution in $4 \%$ rabbit serum. Cells were washed, mounted on glass slides, and photographed as described above for tubulin III. All controls with no primary were negative.

\section{Statistical analysis}

All experiments were repeated at least four times using different preparations of $\mathrm{OE}$ cultures and reagents. The data in individual experiments were presented as mean \pm standard error, and statistical analysis (One way ANOVA, Post-hoc Bonferroni Corrected t-tests) was performed using Sigmaplot software.

\section{Results and discussion}

\section{Characterization of olfactory epithelium cultures}

We used a modified protocol to culture olfactory epithelium (OE) cells derived from post-natal mice [26,27]. At 4 days in vitro (DIV) the neuronal precursors and sensory neurons migrate out of the explant and establish as two large halos (Figure 1). The inner halo, which is closer to the explant, is primarily composed of densely populated,

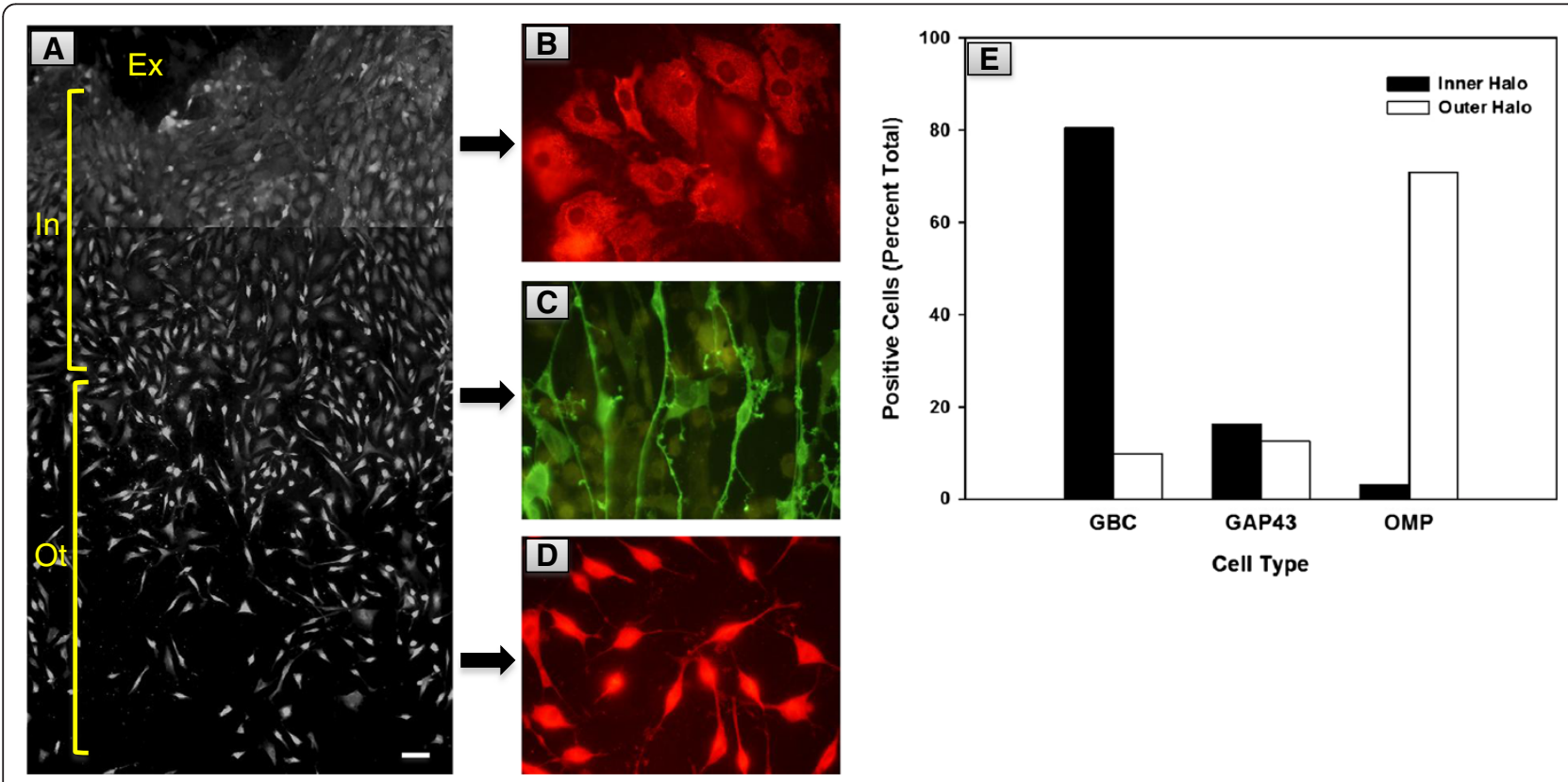

Figure 1 Characterization of the OE culture. (A) Two contiguous phase contrast pictures of the OE culture at 8 DIV were merged to depict the location of the explant (Ex), and the inner (In) and outer (Ot) halos. Scale bar $=50 \mu \mathrm{m}$. Representative morphologies of cells immunostained for GBC1 (B), GAP43 (C) and OMP (D) in the OE culture. (E) Quantification of the cell types in the inner and outer halos in OE cultures. 

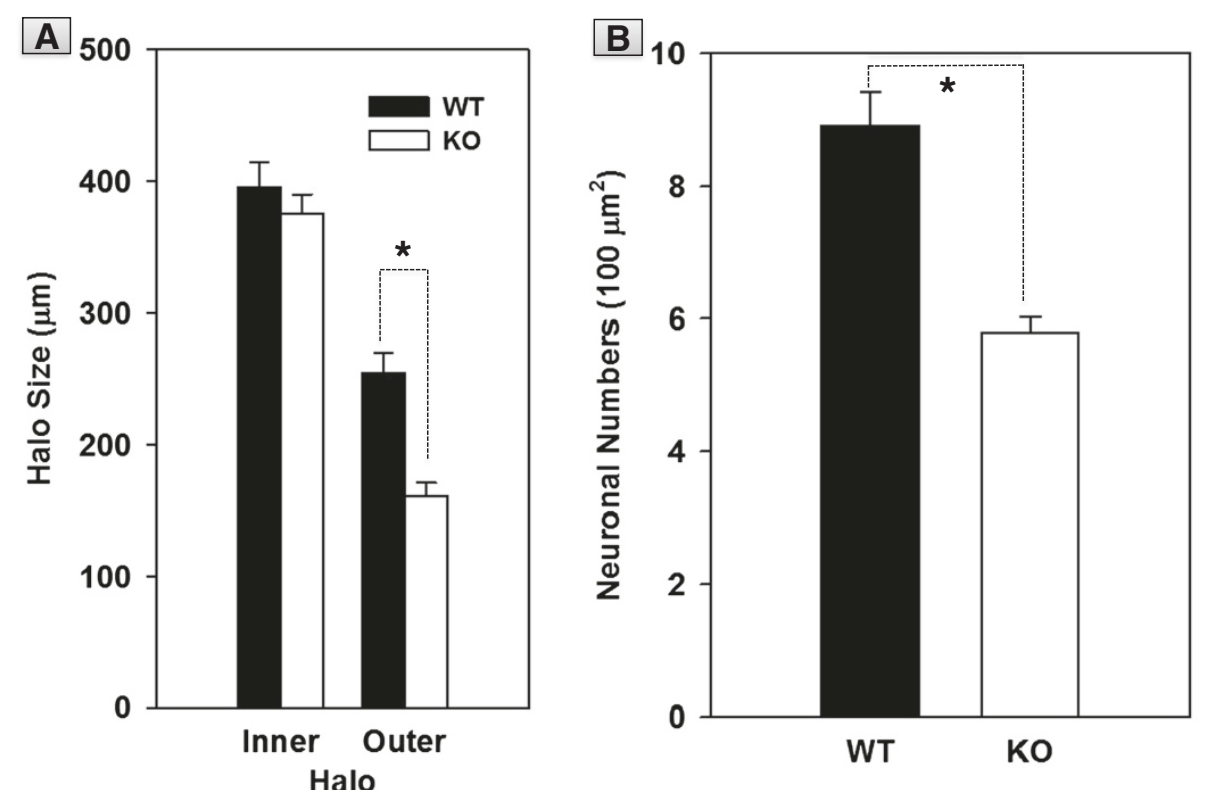

Figure 2 Effects of apoE deficiency on halo size and neuronal numbers in OE cultures. (A) Inner halo size was comparable in OE cultures derived from WT and apoE KO mice. In contrast, outer halo was significantly $\left({ }^{*} p<0.001\right)$ larger in WT mice cultures than in apoE KO cultures. (B) Neuronal numbers were also significantly $\left({ }^{*} p<0.001\right)$ higher in the WT cultures versus apoE KO cultures.

irregular shaped cells. About $80 \%$ of the cells in the inner halo were positive for GBC-1, a marker for globose basal cells in the mature OE $[28,29]$. Most of the cells in the boundary of the inner and the outer halo stained for the growth-associated protein (GAP) 43, a marker for immature olfactory sensory neurons in the OE [30-32]. The cells in the outer halo were bipolar in shape and were sparsely distributed. These cells expressed olfactory marker protein (OMP), a marker for mature sensory neurons in the $\mathrm{OE}$ $[33,34]$. In essence, the $\mathrm{OE}$ culture technique described herein provides an in vitro model system to study the various cell types that normally resides in the OE.


Figure 3 Effects of apoE deficiency on neurite outgrowth in OE cultures. Phase contrast photographs of representative neurons in OE cultures derived from WT (A) and apoE KO mice (B). Cultures were grown for 8 days, fixed and photographed. Scale bar $=25 \mu \mathrm{m}$. (C) Quantification of the effects of apoE deficiency on neurite outgrowth. Neurite outgrowth was significantly ${ }^{*} p<0.001$ ) longer in WT cultures than in apoE KO cultures. 


\section{ApoE promotes differentiation of basal cells to olfactory sensory neurons}

We first compared halo size in $\mathrm{OE}$ cultures from apoE $\mathrm{KO}$ mice with that from age- and strain-matched WT mice (Figure 2A). The size of the inner halo, which is primarily composed of $\mathrm{GBC}-1^{+}$basal cells, was comparable in WT and apoE KO cultures. In contrast, the size of the outer halo, which is primarily composed of cells with bipolar outgrowths, was significantly $(\mathrm{p}<0.001)$ smaller in the apoE KO mice than that in the WT mice cultures. To directly test if apoE deficiency leads to decreased neuronal numbers, we performed tubulin III immunocytochemistry, which is a marker for neurons [35-37]. Fewer tubulin III positive cells were in the outer halo of the KO mice than that in the WT mice culture (Figure 2B). These data suggest that apoE deficiency in the apoE KO mice leads to reduced differentiation of basal cells to sensory neurons in the OE cultures.

Our results are consistent with previous studies that have also shown a critical role for apoE in neuronal differentiation. ApoE is known to modulate factors that are important for neurogenesis, including WNT2 and granulin $[38,39]$. In addition, apoE also promotes survival of neurons in normal and injured nervous system by up regulating pro-neurogenic factors like $\mathrm{Bcl} 2$ [40]. The precise mechanism whereby apoE promotes basal cell differentiation to olfactory sensory neurons is not clear, and has to be examined in future studies.

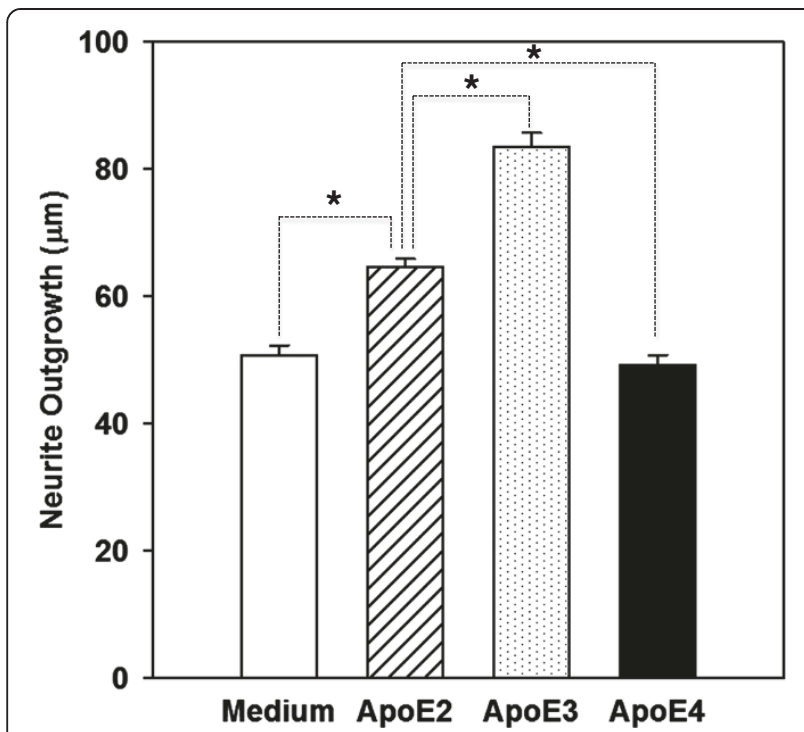

Figure 4 Effects of human apoE on neurite outgrowth in $\mathrm{OE}$ cultures. Two-days old cultures from apoE KO mice were grown in medium alone, and in medium containing $5 \mu \mathrm{g} / \mathrm{ml}$ of human apoE2, human apoE3, or human apoE4. Medium was changed every two days, and apoE re-added. Cultures were fixed at 8 DIV, and neurite outgrowth $\left({ }^{*} p<0.05\right)$ was measured in tubulin III immunopositive neurons as described under Methods.

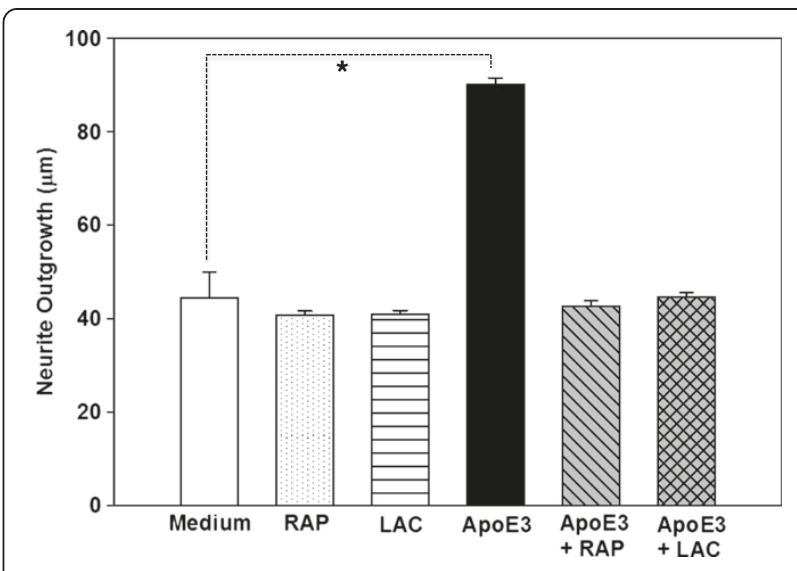

Figure 5 Effects of blocking lipoprotein receptor, LRP, on differential effects of human apoE on neurite outgrowth in $\mathrm{OE}$ cultures. Two-days old cultures from apoE KO mice were incubated for $1 \mathrm{~h}$ in medium alone or in medium containing receptor associated protein (RAP) $(5 \mu \mathrm{g} / \mathrm{ml})$ or lactoferrin (LAC, $10 \mu \mathrm{g} / \mathrm{ml})$. Following incubation with RAP or LAC, human apoE isoform $(5 \mu \mathrm{g} /$ $\mathrm{ml}$ ) was added to the medium and incubation was continued for a total of 8 days. Medium was changed every two days, and test reagents re-added. Cultures were fixed, and neurite outgrowth ( $\left.{ }^{*} p<0.05\right)$ was measured in tubulin III immunopositive neurons as described under Methods.

\section{ApoE facilitates neurite outgrowth in OE cultures}

To examine if apoE is important for neuronal process outgrowth we measured neurite outgrowth at 8 DIV. Our measurements revealed that neurons in the apoE KO cultures had significantly $(\mathrm{p}<0.001)$ shorter neurite outgrowth than those from neurons in the WT cultures (Figure 3). These results are consistent with previous studies that showed diminished neurite outgrowth in embryonic and adult neuronal cultures derived from apoE KO mice $[25,41]$. ApoE may have increased neurite outgrowth directly by redistributing lipids released from degenerating olfactory explant to newly differentiated neurons that are in dire need for lipids to extend neurites. Alternatively, apoE could have indirectly modulated neurite outgrowth by modulating factors that are critical for extension of neuronal processes.

Human apoE isoforms have differential effects on neurite outgrowth in apoE KO cultures

We next examined the effects of purified human apoE on neurite outgrowth in $\mathrm{OE}$ cultures derived from apoE KO mice. Purified human apoE $(5 \mu \mathrm{g} / \mathrm{ml})$ was added to a 2 DIV culture. The medium was replaced every two days and apoE was re-added. Neurite outgrowth was measured at 8 DIV. Cultures incubated with apoE2 had significantly longer neurite outgrowth as compared to cultures grown in medium alone (Figure 4). Similarly, apoE3 treated cultures had significantly longer neurite outgrowth than those cultures treated with apoE2 or 
medium alone. In contrast, apoE4 treatment did not have an effect, with neurite outgrowth comparable to those in cultures incubated with medium alone. This finding is in striking contrast with other studies that have shown that apoE4 decreases neurite outgrowth in cell lines, and dissociated cell culture systems [25,42-44]. The reasons for this discrepant result are not clear, but differences in culture paradigm, that is, explant versus dissociated neuronal cultures, and culture medium composition could have contributed to this anomaly.

\section{The LRP mediates the isoform-specific effects of apoE on neurite outgrowth in OE cultures}

Previous studies have shown that LRP, a major lipoprotein receptor, plays a critical role on neuronal structure and function, including neuronal differentiation and process outgrowth [25,45-47]. Therefore, we examined if the effects of apoE on neurite outgrowth is mediated by the LRP. In this experiments we blocked the LRP using lactoferrin and RAP, and then examined if human apoE3 treatment can increase neurite outgrowth in OE cultures [48-50]. Lactoferrin and RAP, at the concentration used in this study, did not have an effect on neurite outgrowth (Figure 5). However, blocking of the LRP with RAP or lactoferrin abolished the neurite outgrowth promoting effect of apoE3, and the length of neurites in apoE3 treated cultures were similar to cultures grown in medium alone. These data suggest that the effects of apoE3 on neurite outgrowth are mediated through the LRP pathway of lipoprotein uptake.

How apoE isoforms differentially modulate neurite outgrowth by using the LRP is unclear. One possibility is that apoE isoforms that are internalized through the LRP are differentially processed in neurons. For example, we previously reported that apoE3 accumulated in both the cell bodies and neurites, whereas, apoE4 accumulated to a lesser extent only in the cell body $[44,51,52]$. The differential accumulation and localization of apoE isoforms resulted in isoform-specific effects on neuronal microtubules that are critical for process growth. Fewer well-formed microtubules, and a greatly reduced ratio of polymerized to monomeric tubulin were observed in apoE4-treated neurons than did neurons treated with apoE3 [44]. Whether or not the effect of apoE isoforms on neurite outgrowth is due to their differential regulation of neuronal cytoskeleton in the $\mathrm{OE}$ culture has to be examined in future studies.

\section{Conclusion}

The results from this study showed that apoE plays a critical role in differentiation and neurite outgrowth in olfactory sensory neurons. Moreover, human apoE-isoforms differentially modulated neurite outgrowth. The apoE2 and apoE3 stimulated neurite outgrowth in OE cultures by interacting with the lipoprotein receptor, LRP. In contrast, apoE4, the isoform of apoE that is associated with $\mathrm{AD}$, failed to facilitate neurite outgrowth.

Previous studies have shown that apoE4 individuals have a significant decline in odor threshold and odor identification, and have delays in processing of olfactory information [14-17,53]. The mechanism underlying these isoformspecific effects of apoE on olfactory function is not clear, but based on results from this study it is tempting to suggest that the inability of apoE4 to foster neurite outgrowth may, in part, underlie olfactory dysfunction in AD. Together, these data suggest a tremendous role for apoE in neurological health, which is modulated by apoE genotype.

\section{Abbreviations}

ApoE: Apolipoprotein E; AD: Alzheimer's disease; WT: Wild-type; LRP: LoWdensity lipoprotein receptor related protein; KO: Knockout; RAP: Receptor associated protein; LAC: Lactoferrin

\section{Competing interests}

The authors declare that they have no competing interests.

\section{Authors' contributions}

$\mathrm{AH}, \mathrm{ML}$, and $\mathrm{AP}$ carried out the research work, prepared the data for publication, and drafted the manuscript. BPN conceived of the study, and participated in its design and coordination and helped to draft the manuscript. All authors have read and approved the final manuscript.

\section{Acknowledgements}

This work was supported in part by an Illinois Department of Public Health grant, National Institute of Health R15 grant and Eastern Illinois University grants. Purified RAP was generously provided by Dr. Dudley Strickland (American Red Cross, Rockville, MD).

Received: 10 May 2013 Accepted: 8 July 2013

Published: 12 July 2013

\section{References}

1. Mahley RW: Apolipoprotein E: cholesterol transport protein with expanding role in cell biology. Science 1988, 240:622-630.

2. Brown MS, Goldstein JL: A receptor-mediated pathway for cholesterol homeostasis. Science 1986, 232:34-47.

3. Weisgraber $\mathrm{KH}$ : Apolipoprotein E: structure-function relationships. Adv Protein Chem 1994, 45:249-302.

4. Zannis VI, Breslow JL, Utermann G, Mahley RW, Weisgraber KH, Havel R, Goldstein J, Brown MS, Schonfeld G, Hazzard WR, Blum C: Proposed nomenclature of apoE isoproteins, apoE genotypes, and phenotypes. J Lipid Res 1982, 23:911-914.

5. Corder EH, Lannfelt L, Bogdanovic N, Fratiglioni L, Mori H: The role of APOE polymorphisms in late-onset dementias. Cell Mol Life Sci 1998, 54:928-934.

6. Corder EH, Saunders AM, Risch NJ, Strittmatter WJ, Schmechel DE, Gaskell PC Jr, Rimmler JB, Locke PA, Conneally PM, Schmader KE, et al: Protective effect of apolipoprotein E type 2 allele for late onset Alzheimer disease. Nat Genet 1994, 7:180-184.

7. Corder EH, Saunders AM, Strittmatter WJ, Schmechel DE, Gaskell PC Jr, Roses AD, Pericak-Vance MA, Small GW, Haines JL: The apolipoprotein E E4 allele and sex-specific risk of Alzheimer's disease. JAMA 1995, 273:373-374.

8. Corder EH, Saunders AM, Strittmatter WJ, Schmechel DE, Gaskell PC, Small GW, Roses AD, Haines JL, Pericak-Vance MA: Gene dose of apolipoprotein E type 4 allele and the risk of Alzheimer's disease in late onset families. Science 1993, 261:921-923.

9. Saunders AM, Strittmatter WJ, Schmechel D, George-Hyslop PH, PericakVance MA, Joo SH, Rosi BL, Gusella JF, Crapper-MacLachlan DR, Alberts MJ, et al: Association of apolipoprotein E allele epsilon 4 with late-onset familial and sporadic Alzheimer's disease. Neurology 1993, 43:1467-1472.

10. Farrer LA, Cupples LA, Haines JL, Hyman B, Kukull WA, Mayeux R, Myers RH, Pericak-Vance MA, Risch N, van-Duijn CM: Effects of age, sex, and ethnicity on the association between apolipoprotein E genotype and Alzheimer 
disease. A meta-analysis. APOE and Alzheimer Disease Meta Analysis Consortium. JAMA 1997, 278:1349-1356.

11. Ohm TG, Scharnagl H, Marz W, Bohl J: Apolipoprotein E isoforms and the development of low and high Braak stages of Alzheimer's diseaserelated lesions. Acta Neuropathol (Berl) 1999, 98:273-280.

12. Schmechel DE, Saunders AM, Strittmatter WJ, Crain BJ, Hulette CM, Joo SH, Pericak-Vance MA, Goldgaber D, Roses AD: Increased amyloid beta-peptide deposition in cerebral cortex as a consequence of apolipoprotein $\mathrm{E}$ genotype in late-onset Alzheimer disease. Proc Natl Acad Sci USA 1993, 90:9649-9653.

13. Arendt T, Schindler C, Bruckner MK, Eschrich K, Bigl V, Zedlick D, Marcova L: Plastic neuronal remodeling is impaired in patients with Alzheimer's disease carrying apolipoprotein epsilon 4 allele. J Neurosci 1997, 17:516-529.

14. Bacon AW, Bondi MW, Salmon DP, Murphy C: Very early changes in olfactory functioning due to Alzheimer's disease and the role of apolipoprotein E in olfaction. Ann N Y Acad Sci 1998, 855:723-731.

15. Calhoun-Haney R, Murphy C: Apolipoprotein epsilon4 is associated with more rapid decline in odor identification than in odor threshold or Dementia Rating Scale scores. Brain Cogn 2005, 58:178-182.

16. Gilbert PE, Murphy C: The effect of the ApoE epsilon4 allele on recognition memory for olfactory and visual stimuli in patients with pathologically confirmed Alzheimer's disease, probable Alzheimer's disease, and healthy elderly controls. J Clin Exp Neuropsychol 2004, 26:779-794.

17. Murphy C, Bacon AW, Bondi MW, Salmon DP: Apolipoprotein E status is associated with odor identification deficits in nondemented older persons. Ann N Y Acad Sci 1998, 855:744-750.

18. Murphy C, Solomon ES, Haase L, Wang M, Morgan CD: Olfaction in aging and Alzheimer's disease: event-related potentials to a cross-modal odorrecognition memory task discriminate ApoE epsilon4+ and ApoE epsilon 4- individuals. Ann N Y Acad Sci 2009, 1170:647-657.

19. Sundermann EE, Gilbert PE, Murphy C: The effect of hormone therapy on olfactory sensitivity is dependent on apolipoprotein E genotype. Horm Behav 2008, 54:528-533.

20. Sundermann EE, Gilbert PE, Murphy C: Apolipoprotein E epsilon4 genotype and gender: effects on memory. Am J Geriatr Psychiatry 2007, 15:869-878.

21. Handley OJ, Morrison CM, Miles C, Bayer AJ: ApoE gene and familial risk of Alzheimer's disease as predictors of odour identification in older adults. Neurobiol Aging 2006, 27:1425-1430.

22. Nathan BP, Nannapaneni S, Gairhe S, Nwosu I, Struble RG: The distribution of apolipoprotein E in mouse olfactory epithelium. Brain Res 2007, 1137:78-83.

23. Nathan BP, Nisar R, Short J, Randall S, Grissom E, Griffin G, Switzer PV, Struble RG: Delayed olfactory nerve regeneration in ApoE-deficient mice. Brain Res 2005, 1041:87-94

24. Nathan BP, Barsukova AG, Shen F, McAsey M, Struble RG: Estrogen facilitates neurite extension via apolipoprotein $E$ in cultured adult mouse cortical neurons. Endocrinology 2004, 145:3065-3073.

25. Nathan BP, Jiang Y, Wong GK, Shen F, Brewer GJ, Struble RG: Apolipoprotein E4 inhibits, and apolipoprotein E3 promotes neurite outgrowth in cultured adult mouse cortical neurons through the lowdensity lipoprotein receptor-related protein. Brain Res 2002, 928:96-105.

26. McCurdy RD, Feron F, McGrath JJ, Mackay-Sim A: Regulation of adult olfactory neurogenesis by insulin-like growth factor-I. Eur J Neurosci 2005, 22:1581-1588

27. Feron F, Perry C, McGrath JJ, Mackay-Sim A: New techniques for biopsy and culture of human olfactory epithelial neurons. Arch Otolaryngol Head Neck Surg 1998, 124:861-866.

28. Huard JM, Youngentob SL, Goldstein BJ, Luskin MB, Schwob JE: Adult olfactory epithelium contains multipotent progenitors that give rise to neurons and non-neural cells. J Comp Neurol 1998, 400:469-486.

29. Jang W, Youngentob SL, Schwob JE: Globose basal cells are required for reconstitution of olfactory epithelium after methyl bromide lesion. J Comp Neurol 2003, 460:123-140.

30. Ramakers GJ, Verhaagen J, Oestreicher AB, Margolis FL, van-Bergen en Henegouwen PM, Gispen WH: Immunolocalization of B-50 (GAP-43) in the mouse olfactory bulb: predominant presence in preterminal axons. J Neurocytol 1992, 21:853-869.

31. Verhaagen J, Greer CA, Margolis FL: B-50/GAP43 Gene Expression in the Rat Olfactory System During Postnatal Development and Aging. Eur J Neurosci 1990, 2:397-407.

32. Verhaagen J, Oestreicher AB, Gispen WH, Margolis FL: The expression of the growth associated protein B50/GAP43 in the olfactory system of neonatal and adult rats. J Neurosci 1989, 9:683-691.
33. Margolis FL: A brain protein unique to the olfactory bulb. Proc Natl Acad Sci USA 1972, 69:1221-1224.

34. Keller A, Margolis FL: Immunological studies of the rat olfactory marker protein. J Neurochem 1975, 24:1101-1106.

35. Burgoyne RD, Cambray-Deakin MA, Lewis SA, Sarkar S, Cowan NJ: Differential distribution of beta-tubulin isotypes in cerebellum. EMBO J 1988, 7:2311-2319.

36. Gu W, Lewis SA, Cowan NJ: Generation of antisera that discriminate among mammalian alpha-tubulins: introduction of specialized isotypes into cultured cells results in their coassembly without disruption of normal microtubule function. J Cell Biol 1988, 106:2011-2022.

37. Lewis SA, Cowan NJ: Complex regulation and functional versatility of mammalian alpha- and beta-tubulin isotypes during the differentiation of testis and muscle cells. J Cell Biol 1988, 106:2023-2033.

38. Morris DC, Zhang ZG, Wang Y, Zhang RL, Gregg S, Liu XS, Chopp M: Wnt expression in the adult rat subventricular zone after stroke. Neurosci Lett 2007, 418:170-174

39. Chiba S, Suzuki M, Yamanouchi K, Nishihara M: Involvement of granulin in estrogen-induced neurogenesis in the adult rat hippocampus. J Reprod Dev 2007, 53:297-307.

40. Sasaki T, Kitagawa K, Yagita Y, Sugiura S, Omura-Matsuoka E, Tanaka S, Matsushita $\mathrm{K}$, Okano $\mathrm{H}$, Tsujimoto $\mathrm{Y}$, Hori M: Bcl2 enhances survival of newborn neurons in the normal and ischemic hippocampus. J Neurosci Res 2006, 84:1187-1196.

41. Narita M, Bu G, Holtzman DM, Schwartz AL: The low-density lipoprotein receptor-related protein, a multifunctional apolipoprotein $\mathrm{E}$ receptor, modulates hippocampal neurite development. J Neurochem 1997 68:587-595

42. Nathan BP, Bellosta S, Sanan DA, Weisgraber KH, Mahley RW, Pitas RE: Differential effects of apolipoproteins E3 and E4 on neuronal growth in vitro. Science 1994, 264:850-852.

43. Bellosta S, Nathan BP, Orth M, Dong LM, Mahley RW, Pitas RE: Stable expression and secretion of apolipoproteins E3 and E4 in mouse neuroblastoma cells produces differential effects on neurite outgrowth. J Biol Chem 1995, 270:27063-27071.

44. Nathan BP, Chang KC, Bellosta S, Brisch E, Ge N, Mahley RW, Pitas RE: The inhibitory effect of apolipoprotein E4 on neurite outgrowth is associated with microtubule depolymerization. J Biol Chem 1995, 270:19791-19799.

45. Herz J, Strickland DK: LRP: a multifunctional scavenger and signaling receptor. J Clin Invest 2001, 108:779-784.

46. Brown MD, Banker GA, Hussaini IM, Gonias SL, VandenBerg SR: Low density lipoprotein receptor-related protein is expressed early and becomes restricted to a somatodendritic domain during neuronal differentiation in culture. Brain Res 1997, 747:313-317.

47. Herz J, Willnow TE: Functions of the LDL receptor gene family. Ann N Y Acad Sci 1994, 737:14-19

48. Kounnas MZ, Haudenschild CC, Strickland DK, Argraves WS: Immunological localization of glycoprotein 330, low density lipoprotein receptor related protein and $39 \mathrm{kDa}$ receptor associated protein in embryonic mouse tissues. In Vivo 1994, 8:343-351.

49. Williams SE, Ashcom JD, Argraves WS, Strickland DK: A novel mechanism for controlling the activity of alpha 2-macroglobulin receptor/low density lipoprotein receptor-related protein. Multiple regulatory sites for 39-kDa receptor-associated protein. J Biol Chem 1992, 267:9035-9040.

50. Willnow TE, Goldstein JL, Orth K, Brown MS, Herz J: Low density lipoprotein receptor-related protein and gp330 bind similar ligands, including plasminogen activator-inhibitor complexes and lactoferrin, an inhibitor of chylomicron remnant clearance. J Biol Chem 1992, 267:26172-26180.

51. Mahley RW, Nathan BP, Pitas RE: Apolipoprotein E. Structure, function, and possible roles in Alzheimer's disease. Ann N Y Acad Sci 1996, 777:139-145.

52. Mahley RW, Nathan BP, Bellosta S, Pitas RE: Apolipoprotein E: impact of cytoskeletal stability in neurons and the relationship to Alzheimer's disease. Curr Opin Lipidol 1995, 6:86-91.

53. O'Hara R, Yesavage JA, Kraemer HC, Mauricio M, Friedman LF, Murphy GM Jr: The APOE epsilon4 allele is associated with decline on delayed recal performance in community-dwelling older adults. J Am Geriatr Soc 1998 46:1493-1498.

doi:10.1186/1423-0127-20-49

Cite this article as: Hussain et al:: Isoform-specific effects of ApoE on neurite outgrowth in Olfactory Epithelium culture. Journal of Biomedical Science 2013 20:49. 